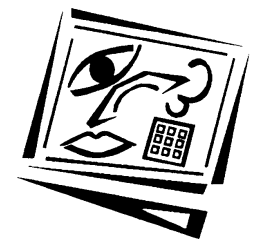

\title{
Emphasising assessment 'as' learning by assessing wiki writing assignments collaboratively and publicly online
}

\author{
Anne Davies, Kerry Pantzopoulos \\ Victoria University \\ Kathleen Gray \\ The University of Melbourne
}

\begin{abstract}
The use of Web 2.0 communication practices in assessment may offer a new approach to assessment 'as' learning, a goal for assessment that is more highly valued than assessment 'of' and even 'for' learning in the literature. This paper describes a case study of a wiki-writing assignment that aimed to achieve this goal. The stakes were high, in that the assignment was worth $100 \%$ of the mark and the assignment was set for a group of tertiary teachers who were enrolled in a unit of study about student assessment as part of a Graduate Certificate in Tertiary Education. This paper analyses how the wiki-writing assignment shaped assessment 'as' learning in four ways, through: finding a language for talking about assessment; collaboration (interaction); dialogue (expression); and inquiry learning (cognition).
\end{abstract}

\section{Background}

The teachers in this case study sought to create an online community of reflective practitioners that would support tertiary educators to deepen their understanding and improve their practice of student assessment. They offered a unit of study about student assessment for 27 higher education and vocational educators enrolled in a Graduate Certificate in Tertiary Education. While the 'Student Assessment' unit was conventional in its coverage of assessment design, strategies, policies and practices, the teachers also wanted participants to develop a personal and profound understanding of assessment. The design of the assessment process was therefore underpinned by three key ideas - that learning would be reached through inquiry, that the inquiry would be contextually connected and initiated by participants' technical, epistemological and ontological questions and finally that the learning process would be enriched through multiple opportunities for online dialogue and collaboration. One intended purpose of the assessment activity was to experience assessment 'as' learning.

\section{Assessment 'as' learning and how it may be achieved}

Assessment is sometimes related to learning using three prepositions (Earl, 2003). Assessment 'of' learning captures the summative tradition of judging performance and measuring outcomes, after formal learning activity. Assessment 'for' learning reflects the importance of formative feedback early and often on practice runs, on rehearsals, on small chunks, during learning activity. Assessment 'as' learning expresses the aspiration that assessment will develop students' capacity to be self-aware and selfmonitoring above and beyond the essential requirements of the formal learning 
activity. Earl and Katz (2006, p. 54) elaborate that, in assessment 'as' learning, what is assessed is "each student's thinking about his or her learning, what strategies he or she uses to support or challenge that learning, and the mechanisms he or she uses to adjust and advance his or her learning".

Earl and Katz (2006) believe that creating a learning environment where students are able to focus on learning rather than getting the right answer, and are able to articulate record and monitor their own learning progress to develop independent learning habits is integral to the assessment 'as' learning process. They consider that quality assessment 'as' learning occurs when students are given the opportunity to challenge their own thinking, discuss alternatives with teachers and peers, openly consider their own and others' ideas, and actively engage in consistent self-reflection, to rethink accurately, adjust and report their learning.

While 'as' is 'the ultimate goal' (Earl, 2003), equated with 'learning that lasts' or 'sustainable assessment' (Boud \& Falchikov, 2005), descriptions of how it is accomplished in practice are scarce. Jenkins $(2009$, p. 163) infers that it may be accomplished inadvertently if we are not aware that how we design assessment shapes the curriculum. Marcangelo and Cartney (2010, p. 4), citing Hatton and Smith (1995), argue that it can be done through a hierarchy of self assessment tasks which act as scaffolding for the learner across a curriculum that supports assessment as learning. Achievement of these tasks initially involves the development of strategies for planning, monitoring, checking and self testing; building on this, the next stage is to develop an ability to analyse what one knows, what one needs to know and matching these together to achieve the task in hand. It also should include an ability to identify what new learning strategies need to be developed. To achieve these skills, the student must be exposed to opportunities to practise these skills within different contexts; to self assess their effectiveness in terms of outcomes achieved, and to receive feedback on their efforts in self assessment.

\section{The potential of wiki-writing to actualise assessment 'as' learning}

According to Kirkwood and Price (2008), the design of assessment "influences not only what parts of a course get studied, but also how those parts are studied.... Appropriately designed assessment that exploits the potential of ICT can change students' approaches to learning" ( p. 5). It seemed to us, then, that traditional approaches to tertiary assessment, or even mainstream approaches to e-assessment (such as Crisp, 2009, p. 2) would be unpromising as a way to tackle the challenge of helping our students to understand assessment 'as' learning. The combination of our frustration, with the inflexibility of university online learning systems and our curiosity about the collaborative possibilities of using Web 2.0 technologies provided the catalyst for us to set up a wiki to support participants' learning.

In particular, the use of Web 2.0 communication practices in assessment appeared to offer a new approach to assessment 'as' learning. As Dohn (2009) says, "Web 2.0 criteria of evaluation do not concern documentation of 'knowledge possessions'. Instead they are concerned with the extent and meaningfulness of participation, along with, for some practices, the scope, usefulness, and quality of the material" (p. 358). Dohn argues that we need to consider our use of Web 2.0 in education essentially as a way of inculcating a set of practices: collaboration; active, open-access, bottom-up participation and interactive multi-way communication; continuous production, 
reproduction, and transformation of material in use and reuse across contexts; openness of content, renunciation of copyright, distributed ownership; and lack of finality, awareness-in-practice of the open-endedness of the activity.

Wikis, in particular, have been said to facilitate a wide variety of authentic, collaborative and reflective learning activities (Duffy \& Bruns, 2006; Benckendorff, 2009; Larusson \& Alterman, 2009). Wiki activities that are well designed and supported by teaching staff have been shown to develop trainee teachers' abilities to undertake assessment (Lai \& Ng, 2011). However, specific pedagogical insights into how wikis may be used effectively for assessment not only 'of' and 'for' but also 'as' learning are limited.

This case study reports lessons learned about using wiki-writing to actualise assessment 'as' learning, through reflection on the experience of being team teachers (Davies and Pantzopoulos) and on field notes gathered by a peer observer (Gray), as well as from thematic analysis of participants' wiki writing and a post-program participant questionnaire (ten were completed and returned). But first we describe the wiki, the assessment task and the workshop program.

\section{Describing and explaining our practice}

\section{The wiki}

We set up a wiki to provide immediate access and support for a process in which participants shared their writings about assessment - promoting a collaborative and dialogic approach to inquiry learning that was situated in the workplace, driven by the institutional commitment to improvement and shaped by self-directed learning, exploration and self-awareness. We chose the free version of the PBworks wiki tool for its ease of use in creating and managing text, hypertext, highlighting, tables, comments, files and multiple pages. Prior to the workshop we created a personal wiki page for each participant and topic pages focusing on a variety of assessment issues with uploaded resources. The shared online inquiry was the assessment task for the unit. It was initiated as participants wrote personal accounts in their wiki pages and continued as they engaged in a process of analysis. All aspects of the inquiry/ assessment task were completed in the wiki and were visible to all group participants.

\section{The task}

In line with the views of Kirkwood and Price (2008) we designed the assessment task knowing that it would determine the nature of the learning experience. We wanted to increase the task's relevance and ownership and provide a foundation for active engagement in critical thinking and real-world problem-solving related to student assessment and so we asked participants to write five personal accounts drawn from their own assessment practices in tertiary education settings. The invitation to participants to initiate the inquiry by focusing on their own experiences and questions also provided us with an opportunity to make connections and integrate what we thought participants might need to know, understand and be able to do by the end of the unit in order to improve their practice, meet the learning outcomes for the unit and get to know the university's current strategic priorities and policies. 
Participants then used a three-step analysis to identify major themes, key words and personal theories within their accounts, taking a structured approach - 'sketch, thread and theorise' - developed by Kruger, Cherednichenko, Hooley and Moore (2001). A three-column table shaped this work and encouraged the articulation of clear connections. Table 1 shows an excerpt from one participant's personal account with their initial three-step analysis connecting sketch (bold highlighted sections), thread or keywords and personal theorising.

Table 1: Excerpt from a participant's 'sketch, thread and theorise' writing

\begin{tabular}{|l|l|l|}
\hline \multicolumn{1}{|c|}{ Account and sketch/main themes } & Thread/keywords & \multicolumn{1}{c|}{ Personal theories } \\
\hline $\begin{array}{l}\text { The first assessment task for the Semester was } \\
\text { due in Week 3. It required students to work } \\
\text { in small groups. The students wished to } \\
\text { choose their own groups. Despite mentioning } \\
\text { at every lecture, making announcements on } \\
\text { WebCT and sending emails 6 students did } \\
\text { not allocate themselves a group. I allocated } \\
\text { these students into Group 31. Despite more } \\
\text { emails encouraging them to ensure the work }\end{array}$ & Group work & $\begin{array}{l}\text { I believe group work } \\
\text { requires team work, } \\
\text { advanced communication } \\
\text { and negotiation skills. }\end{array}$ \\
$\begin{array}{l}\text { was completed the students handed the } \\
\text { assessment piece in individually. I was } \\
\text { lenient and did not deduct marks however } \\
\text { made comments on their assessment } \\
\text { informing them that Assessment 2 and 4 for } \\
\text { the subject were group assessments and as } \\
\text { such they were required to submit one piece } \\
\text { of work per group. As a result of not } \\
\text { deducting marks these same students have } \\
\text { not participated and become problems in } \\
\text { these future assessments. }\end{array}$ & Non participation & $\begin{array}{l}\text { I believe that by being } \\
\text { lenient it has resulted in } \\
\text { poor student conduct in } \\
\text { the other assessments. }\end{array}$ \\
\hline
\end{tabular}

Participants followed this analysis with reflective comments, identifying questions and areas of interest that had emerged, that might lead them to reading, research and development. For instance, at this point one participant noted, 'I have decided to focus on group work paying particular attention to designing the assessment processes'.

As participants crafted and analysed their writing, we modelled formative feedback in the wiki's comments boxes and invited everyone in the group to utilise the comments boxes and contribute to each other's pages in the spirit of conversation and inquiry. Peer feedback was included to encourage each individual not only to contribute to their peers' inquiry but also to increase their capacity to recognise new learning and become aware of a range of assessment approaches and issues, making it plain to see that knowledge is uncertain and that often there are no black and white answers.

We had designed an assessment rubric that we posted as a grid into each personal wiki page so that it could be used as a framework for monitoring, checking and self-testing throughout the unit. This was high-stakes assessment, with the assignment worth $100 \%$ of a participant's mark in this unit of study. The design of the assessment rubric was influenced by Biggs' SOLO (Structured Observable Learning Outcomes) taxonomy (Biggs \& Tang 2007) and was criterion-referenced, based on specified explicit criteria. The rubric was intended to make it more straightforward for participants to judge their own and their peers' progress and performance. On one axis, the rubric set out the intended learning outcomes: 
- Participants know and respond to the range of learning needs of their students both in terms of the knowledge they bring and the learning approaches they prefer.

- Participants design assessment that identifies and reports student learning, provides feedback to students about their learning, and informs further planning of teaching and learning.

- Participants provide prompt, informed and constructive feedback to students on their work.

- Participants ensure consistency in assessing student work by applying consistent criteria and standards in making assessment judgments.

- Participants monitor student achievement and maintain accurate records of their progress.

On the other axis, the rubric set out the levels of learning and associated grades:

- Extended abstract: Student conceptualises at a level extending beyond what has been dealt with in the actual teaching. Can generalise to a new area. HD (80-100\%)

- Relational: Indicate orchestration between facts and theory, action and purpose. Understanding of several components which are integrated conceptually. Can apply the concept to familiar problems or work situations. D (70-79\%)

- Multi structural: Indicates understanding of boundaries but not of systems. Understanding of several components but the understanding of each is discrete. Disorganised collection of ideas or concepts around an issue. Has not been able to relate the items in the list. C (60-69\%)

- Uni-structural: Concrete, minimalistic understanding of an area. Focuses on one conceptual issue in a complex case. P (50-59\%)

- Pre-structural: Task is not attacked appropriately; the student hasn't really understood the point and uses too simple a way of going about it. N (0-49\%)

In the culminating activity both teachers and participants added summative comments into the rubric grid. Peer participation in this aspect of the assessment was designed to promote the development of self-aware, self-monitoring and self-testing participants, that is, participants who would recognise and share each other's progress and achievements beyond what conventional assessment activities required (Griffin, 2000).

\section{The workshop}

The Student Assessment unit began with a full day, face to face workshop, structured into three sessions, followed up with online activity for the rest of the semester.

In the first session, we started by reviewing assessment practices participants had already used and creating a concept map of assessment issues, making connections with our current knowledge of the literature and university strategic objectives and policies. We introduced the wiki and viewed pre-prepared personal pages and pages that focused on different assessment topics. We invited participants to use these topic pages to share references they thought might be of interest to the group. We highlighted the need to ensure that personal theorising was not only underpinned by personal experience but also by theoretical literature. We then asked participants to identify any questions they had about assessment and sort them into categories to explore the dimensions of potential inquiries (Kruger \& Cherednichenko, 2006). 
In the second session, we moved to the computer lab and provided an opportunity for the group to look more closely at what was required. Together we examined examples of previous students' completed work. Using a process that drew on the ideas of praxis inquiry and Kolb's experiential learning cycle (Burridge, Carpenter, Cherednichenko \& Kruger, 2010) participants started the writing task, describing their own assessment experiences in personal accounts. The activity focused on identifying and recording dilemmas in current assessment practice and trialling the process of analysis by 'sketching, threading and theorising' in the accounts.

The last session was shaped by the question: What can we do to support each other? As wikis depend upon and foster interaction between participants, interaction in the workshop was an ideal opportunity to establish relationships characterised by respect and responsiveness that would carry from the workshop into the online environment (Brookfield \& Preskill, 2005). We modelled respectful interactions and negotiated wiki protocols for effective online communication. We encouraged participants to ask each other clarifying questions and discussed the difference between providing warm (congratulatory) feedback, and cool (wondering) feedback when making comments in the wiki. We encouraged everyone to be part of a learning community to share ideas, resources and self-reflections and to give, receive and respond to peer feedback, publish all of their assessment activity for all participants to see and contribute to assessment of their peers online.

\section{Analysing our practice}

We encouraged and supported participants to reflect on, articulate and monitor their own learning, analyse what they know, challenge their own thinking, consider the ideas of others, rethink, and adjust their own learning publicly online. We also asked them to self and peer assess and contribute to each other's learning. Working in this way meant that we used the wiki for assessment 'of', 'for' and 'as' learning.

Typically assessment 'of' learning would be achieved through the completion of a common task followed by a private exchange between teacher and individual student. However, in this instance the task was negotiated and shaped by each individual's initiating questions, personal accounts and reflections, and the analysis and the feedback were all accessible to all participants. While the final responsibility for grading was the teachers', the whole group could use the rubric grid in each personal page to collaborate in giving summative feedback. The collaborative, formative dimension of the assessment process (i.e. assessment 'for' learning) involved participants drafting and redrafting their work in the wiki in response to feedback contributed as comments by teachers and also by fellow participants. The comments function of the wiki facilitated threaded conversations connected to each person's personal page and to specific topic pages.

Moreover, learner-owned, generative assessment 'as' learning was achieved because the wiki supported and shaped participants engaging in an open and collaborative process of inquiry through which they identified areas for improvement in their personal assessment practices. In-depth analysis of the activities undertaken by participants provides evidence that assessment 'as' learning was facilitated through the use of wiki writing and the possibility for online interaction connected to the writing. 


\section{Four layers of engagement shape assessment 'as' learning}

Analysis of data from this case suggests four layers of assessment 'as' learning. Mirroring Habermas's (1996, p. 119) ideas about the foundations for communicative action and the process of reaching understanding, the first dimension relates to finding a language for talking about assessment and this is followed by three further dimensions - collaboration (interaction), dialogue (expression) and inquiry learning (cognition).

\section{Finding the language of assessment}

The wiki created a space to connect the personal, practical and professional language of assessment - participants' personal experiences were heard, professional practices were described and the posting of online references meant that the language of the institution and the broader educational community was included.

At an individual level, each participant brought their own language of reflection to the group by posting accounts, comments and feedback into the wiki. Through sharing their work and ideas participants became aware of a range of approaches to solving issues that were complex and had no one answer. As Participant 17 reflected:

During the follow-up discussions ... I realised that there are always alternatives, and that communicating with colleagues and experts will always fill in the blanks in my mindset.

At a cultural level, the language of assessment practices was articulated in personal accounts, and extended in the 'sketch-thread-theorise' process. Teachers are often isolated with few opportunities to work collaboratively (Cochrane-Smith \& Lytle, 1999), so by bringing experiences and ideas from the private into the public realm each participant revealed the language they used to think about assessment and gave their peers something to think about. Because the assessment process was initiated with personal accounts a wide range of topics emerged.

At a societal level, the wiki provided a mechanism for connecting with local, national and international issues and ideas about assessment in tertiary education settings. During the process of redrafting work, participants were engaged in learning the language of the assessment literature as well as the language of university policies. As Participant 5 noted:

Now I am better able to recognise signs of low motivation and less likely to dismiss it as laziness. Once recognised, I now have the resources to use to get in early and use motivational and engagement strategies from the [university's] student centred learning policies and Race's texts.

By including the language of individual practice and experience, participants felt a high level ownership for their own learning. Showing the link between recording personal accounts, reflection and improving practice, Participant 1 observed:

I didn't think I would have enough material for [writing personal accounts] ... I was surprised to find that there have been a few [things] that I am still pondering ... I can see I need to focus on learning skills, setting curriculum, managing learning environments, and designing assessment tasks. 
Having engaged in the process of articulating their own experiences and then reading and making connections with institutional and professional resources, participants were well equipped to begin their work together.

\section{Collaboration}

Most (71\%) respondents to the questionnaire reported that they felt that their peers had displayed collaborative work habits. It seems to us that there were three significant factors in achieving a collaborative online space. The first emerged as participants made their practice public, the second was connected to the opportunity to work collegially and build friendships and the third emerged in the exercise of mutual support and sharing.

\subsection{Making practice public}

Collaboration began as participants began to reveal their experiences by posting their personal accounts into the wiki. As Arendt (1958) explains, in bringing private thoughts into the public realm, we are inviting each other to visit our experiences. In effect the process of making assessment practices public initiated the collaborative dimension of inquiry learning. Participant 6, for instance, observed the value of the wiki in both helping her to 'see' what others had done and feel part of the profession:

By seeing how others have interpreted the assessment questions I can see if I am on the right track. Also, seeing that other lecturers experience the same issues as me [makes me feel] I'm not alone.

While there was a feeling of excitement as participants began to share their experiences publicly in the wiki, many reported feeling resistant, apprehensive, anxious, uneasy and nervous. The challenge of making your work public, revealing private details and opening yourself up to criticism was especially confronting for first time users. As Participant 8 commented to another:

I think you have shown a brave capacity to think about your role as a teacher in general as well as the role of assessment in particular. I think you have shown this in the way you wrote about how you reacted to the different situations in which you found yourself and your conversations with colleagues, peers and students.

The wiki's log of interaction showed everyone spent time reading other people's work in the wiki. One participant revealed she felt like she was intruding or spying by reading other people's pages but most participants indicated they enjoyed reading each other's work. They felt the opportunity to read colleagues' work was a privilege, and useful because it provided an insight - in this way they got new ideas and valued seeing how others had learned from their experiences. There was a strong alignment with Earl and Katz's (2006) views about the value of students recording their own learning as the wiki provided ideas for others about solving problems, adjusting, rethinking, and articulating learning.

Participants expressed gratitude that other people were reading their work and were thankful for the response adding comments such as Participant 15: 'Thanks for spending the time to read and comment on my assignment. Very much appreciated.'

On reflection, most participants felt it was good to publish and share their assessment in the wiki. However, we discovered that wiki work does not suit everyone and for 
some it was quite a challenge to shift from traditional academic practices to this new public and collaborative environment. As Participant 10 confided:

I am a very old fashioned and stereotyped person and have not got used to [using the] Wiki yet. Thanks to this course, I have been given the opportunity to know about the Wiki and use it ...

Knowledge of these views challenges us to improve our workshop design to better prepare participants for online engagement and collaboration.

\subsection{Collegiality and friendships}

Participants appreciated the interactive nature of the wiki assessment and talked about the significance of learning together and feeling as though they were part of a group. We believe that using the wiki both depended on and fostered interaction between participants and teachers. We observed online interactions and noted that participants appreciated getting ideas and learning something new through a collegial process.

We also identified the significance of friendships as those participants who knew one another were more likely to comment and give feedback on each other's pages. This observation about the importance of feeling close to one another alerted us to the significance of building relationships and trust within the group as an important step in supporting dialogue and collaboration. While the intellectual dimension of the relationship was central, participants also expressed their appreciation of collegiality and friendship as Participant 12 commented:

Dear colleagues, Thanks very much for walking me through this course. Your great efforts and companionship are highly appreciated.

\subsection{Supporting and sharing}

The records of interaction in the wiki show that the wiki was a tool for sharing references, providing procedural and intellectual support and raising challenging issues. And Participants 7, 13 and 22 respectively, indicated their appreciation by thanking each other:

Thanks for the ICT references, I look forward to reading them ...

Thanks very much for keeping me in the loop with our common areas of interest ...

Thanks for raising the low SES student issue. It is a very interesting and important social and economic problem in terms of social equity and equality ...

We sought to build a learning environment in which participants felt comfortable to express their ideas, engage in professional conversation and seek help when needed. As teachers we appreciated the supportive and sharing environment as it meant that participants could benefit from a range of people, not just the teachers.

\section{Professional dialogue}

Over the semester-long unit teachers and participants wrote close to 20,000 words using the comments function of the wiki and participants observed that the wiki was a 'very handy platform for communication', that it facilitated ideas being expressed in 'a less rigid format and (also) enabled more flexibility'. An analysis of the wiki provides evidence of three kinds of professional dialogue: self reflection, collegial conversations, and feedback from teachers and peers. 


\subsection{Self-reflective dialogue}

The shape of the assessment demanded self-reflective dialogue and participants reported an increasing self awareness through self reflection, self monitoring and self critique (Earl \& Katz, 2006). In particular, participants posted self-reflective comments as they identified areas for inquiry; for example Participant 3 recorded the decisions she had made to better understand assessment and improve her practice:

I will do more research and read about how game based assessments can be used more to enhance learning. Further I will be conducting an evaluation at the end of the semester to get student feedback on the strategies discussed above.

In the culminating comments at the end of the inquiry process there was evidence of the shift from critique to learning to changed practice. Reflecting on articulated dilemmas, Participant 20 indicated a new understanding about learning and an awareness about how her practice might change:

I've learned through this assessment that by holding too much control over the assessments and by forcing students to participate without first attempting to build their confidence I may have been creating a resistance to learning ...

Our analysis of self-reflective dialogue shows evidence of reflection on practice. In particular there is evidence of participants seeking, confirming and disconfirming evidence and personal learning through critical discourse and assumption hunting, and this is in line with Brookfield's (1995) ideas. Further, this process often initiated collegial conversations about lessons learned, thereby aligning with Earl \& Katz's (2006) ideas that assessment 'as' learning incorporates metacognitive processing that challenges and advances learning.

\subsection{Collegial conversations}

In addition to self reflective dialogue participants were also asked to post comments 'in the spirit of conversation and inquiry'. Despite one participant suggesting that she didn't have much to offer ('I think I'm learning more than helping others at the moment'), numerous threaded conversations and collegial exchanges occurred that provided evidence of professional exchanges based in trust, mutuality and reciprocity. For instance, Participant 4 commented:

I've been looking at your wiki ... I read through your proposed assessment pieces ... I am not sure if guiding them through the process step-by-step is really going to address that core issue of non-participation. I like your idea of getting the students to write a reflective piece about their experience of the group ... I look forward to seeing how successful you are! .... and will be trialling a few things myself.

In particular, the wiki facilitated assessment 'for' learning modelling the importance of early and frequent formative feedback from peers. We encouraged participants to use the comments function to give constructive peer feedback to improve their work. Participants also expressed their appreciation, acknowledging the value of the feedback in improving their assessment practices, and, as Crisp (2009) suggests, they found that frequent feedback resulted in improved practices, for example Participant 11:

... huge thanks to you all for your great feedback, I feel that all comments I have received have been very valuable and have really helped me develop my student assessment techniques to better benefit the students ... 
Some participants only felt happy giving positive feedback, and one noted that by communicating on a professional rather than a personal level discussion reached a deeper level more easily. There was, however, a perception that cool (as opposed to warm) feedback involved criticism and there was a strong feeling in the group that they did not want to be in a position of having to make judgments about their peers' work. This translated into reluctance about giving feedback in the rubric grid. As Participant 15 said:

I had no problem with giving and receiving feedback but I don't feel comfortable about having to make judgements about others' work like filling out the marking rubric.

On reflection, we plan to provide participants with more opportunities to discuss and practise writing comments in the rubric grid and explore the relationship between their summative feedback and allocating final grades.

\subsection{Teacher feedback}

A common complaint from online learners is the low level of teacher feedback and responsiveness, and Brookfield and Preskill (2005) argue that maintaining a social presence online is a strong predictor of student satisfaction. From their perspective, building a social presence helps to counter an environment that is uninviting and might cause loneliness, uncertainty and loss of confidence. Additionally, Huba and Freed (2006) advocate giving learners a sense of how they are doing when they try something new.

Based on participants' comments in the wiki we believe that our wiki provided an ideal platform for sharing resources connected to each participant's particular interests, providing procedural information about the wiki, the assessment task and the rubric as well as responding to individual contributions on personal pages, connecting people and ideas. Participants thought the feedback from the teachers was organised and supportive and that it 'engendered a collegial environment'. They appreciated responses that were detailed, focused on improvement, prompt and timely, helpful and constructive, respectful, positive and without a feeling of hierarchy. Yet in establishing an expectation that there would be teacher feedback we had to be honest about the likely frequency of teacher participation. We agree with Brookfield and Preskill (2005) that it is important to be explicit about expectations to avoid the impression that teachers will be constantly available and always respond immediately.

\section{Inquiry learning}

The fourth dimension of using the wiki 'as' learning was achieved through the space it created for participants to work towards the cognitive, innovative and creative aspects of improving practice. Having engaged with the process of documenting practice, seeking explanations, and developing personal theories, participants began planning for change. They took an independent approach rather than following a predetermined course of learning (Griffin, 2000). Reporting was more descriptive and developmental, and progress was shared with the group rather than through a private exchange between participant and teacher. This inquiry process was enhanced by a commitment to documenting practice, attention to making connections and seeking explanations, explicit personal theorising and an expectation that the process would lead to changed and improved practice. 


\subsection{Documenting practice}

Participants appreciated the opportunity to situate their inquiry in the workplace with the goal of improving their professional assessment practice. Participant 25 noted the value of systematic inquiry:

Often I have all these thoughts and theories swimming around in my head, but getting it down in an orderly, disciplined manner has enhanced my understanding of assessment and my issues with it ... so it's good to distil this particular type of assessment task down to the key issues.

The assessment framework and active wiki writing and interaction enacts assessment 'as' learning as it provided participants with multiple opportunities to record and reflect on their own learning (Earl \& Katz, 2006).

\subsection{Connecting and explaining}

Within the wiki each person focused on their identified learning goals (rather than getting the right answer) and appreciated the resources that were shared on the wiki. Participants noted that locating relevant research and reading resources helped to considerably broaden their understanding of issues. Combining perspectives from peers and the literature allowed participants to comment on, review, appraise and evaluate their own effectiveness as learners and teachers and to plan for improvement. For instance, Participant 21 noted how the process had broadened her understanding of plagiarism and opened her eyes to other ways of preventing plagiarism so that she would now take a 'multi-faceted approach rather than one solution'.

In doing so, participants were able to connect their own learning with other people's approaches and ideas and then use the rubric grid to achieve what Earl and Katz (2006) call self-awareness and self-monitoring.

\subsection{Thinking and personal theorising}

Participants' wiki writing revealed that they were actively engaged in considering and challenging their thinking (Earl \& Katz, 2006) and the assessment task encouraged participants to think deeply about the issue or idea that they were most interested in. Indications of wondering and thoughtfulness were evident in the questions that participants recorded on their personal pages, the reflections and comments that referred to emerging realisations and the metacognitive observations about the value of thinking and rethinking.

But that was only one dimension; everyone else's thinking and explaining was visible too. Participants felt that the teachers had created a trusting and safe environment for democratic dialogue by negotiating online etiquette and modelling respectful relationships and conversations. Participants' comments indicate that these conditions can be connected with an environment that fosters open inquiry, the emergence of alternative ideas and the identification of weaknesses, strengths and new ways forward (Marcangelo \& Cartney, 2010). Participant 14 posted a comment making the link between looking at other people's work and gaining an insight into many other issues.

\subsection{Changing practice}

The assessment process was a generative inquiry process and by the end of the semester participants were planning for the future based on their learning. In all instances participants reported successful change or plans for improved practices. Indicating that generative practice is an ongoing process many participants admitted 
they had more to learn. Participants 19 and 12 respectively, indicated they had identified new questions, new goals and new areas for further inquiry:

\author{
I have read some material on using Web 2.0 technology in group work, and feel that \\ my students would benefit from using some of these tools. I intend to investigate this \\ further for next year. \\ ... the student assessment unit wiki did broaden my knowledge of some things \\ because of the way it was structured. I hope to continue using this wiki to develop the \\ assessment in my subjects.
}

It is our belief that the new inquiry strategies that have been used and the new knowledge of online technologies will provide support for these new investigations.

\title{
Conclusion
}

In this case, using a wiki to emphasise assessment 'as' learning created a rich learning experience where professional outcomes were enhanced. This quality of engagement, often difficult to achieve even in a classroom setting, was made possible through the use of simple but effective wiki technology. The wiki provided new opportunities for participants to make their practice public and to then to work collaboratively and systematically to inquire into and improve their assessment practice in tertiary education settings.

The assessment design seems to have provided what Marcangelo and Cartney (2010, p. 4) refer to as a hierarchy of self assessment, although it may be more like a web. This assessment task provided participants with multiple strategies for experiencing a public learning process built on collaboration, professional dialogue and inquiry. They focused on themselves as learners, indicating a 'sensitive and self-critical, subjective perspective' (Stenhouse, 1975, p. 157) towards their inquiry. They used personal accounts to voice uncertainties and questions and in doing so provided a vehicle for conversation that was openly respectful. They shared different ideas and points of view and avoided the possibility of becoming isolated by differences. The opportunity to tell their stories led to both personal and professional recognition showing, as Sachs (2003, p. 148) suggests, that the 'diversity of people's expertise is a resource to be taken advantage of and fostered.'

Interestingly, we learned from our reflection on this case that while our assessment design was connected with the criteria suggested by Earl and Katz (2006) - that is, it encouraged each participant to think about their learning, it provided strategies to support or challenge that learning, and mechanisms to adjust and advance learning these were not explicitly part of our assessment criteria and therefore not explicitly valued. This will be rectified in the subsequent delivery of this program to emphasise that both the assessment knowledge and the reflective inquiry process are valued.

We hope that this approach to using a wiki to emphasise assessment 'as' learning may be useful to other educators who wish to assist their students to achieve a greater capacity to be self-aware and self-monitoring.

\section{Acknowledgments}

We wish to acknowledge contributions made by the participants in the unit of study "Student Assessment". Support for this publication has been provided by the 
Australian Learning and Teaching Council Ltd, an initiative of the Australian Government Department of Education, Employment and Workplace Relations. The views expressed in this paper do not necessarily reflect the views of the Australian Learning and Teaching Council.

\section{References}

Arendt, H. (1958). The human condition. Chicago and London: The University of Chicago Press.

Benckendorff, P. (2009). Evaluating wikis as an assessment tool for developing collaboration and knowledge management skills. Journal of Hospitality and Tourism Management, 16(1), 102-112. http:/ / www.atypon-link.com/AAP/doi/abs/10.1375/jhtm.16.1.102

Biggs, J. \& Tang, C. (2007). Teaching for quality learning at University: What the student does. (3rd ed.), Berkshire, England: Society for Research into Higher Education and Open University Press, McGraw-Hill Education.

Boud, D. \& Falchikov, N. (2005). Redesigning assessment for learning beyond higher education. In A. Brew \& C. Asmar (Eds.), Higher education in a changing world: Research and Development in Higher Education, 28. Proceedings of the 2005 HERDSA Conference (pp. 34-41). Sydney: HERDSA. http:/ / conference.herdsa.org.au/2005/pdf/refereed/ paper_398.pdf

Brookfield, S. (1995). Becoming a critically reflective teacher. San Francisco, CA: Jossey-Bass.

Brookfield, S. D. \& Preskill, S. (2005). Discussion as a way of teaching: Tools and techniques for democratic classrooms. 2nd ed, San Francisco, CA: Jossey-Bass.

Burridge, P., Carpenter, C., Cherednichenko, B. \& Kruger, T. (2010). Investigating praxis inquiry within teacher education using Giddens' Structuration Theory. Journal of Experiential Education, 33(1), 19-37.

Cochran-Smith, M. \& Lytle S. (1999). The teacher researcher movement: A decade later. Educational Researcher, 28(7), 15-25. http:/ / dx.doi.org/10.3102/0013189X028007015

Crisp, G. (2009). Designing and using e-assessments. HERDSA Guide. Milperra, NSW: Higher Education Research and Development Society of Australasia.

Dohn, N. (2009). Web 2.0: Inherent tensions and evident challenges for education. International Journal of Computer-Supported Collaborative Learning, 4(3), 343-363. http: / / dx.doi.org/10.1007/ s11412-009-9066-8

Duffy, P. \& Bruns, A. (2006). The use of blogs, wikis and RSS in education: A conversation of possibilities. (pp. 31-38). In Proceedings Online Learning and Teaching Conference 2006 (pp. 3138), Brisbane. http: / / eprints.qut.edu.au/5398/1/5398.pdf

Earl, L. (2003). Assessment of learning, for learning and as learning. In Assessment as learning: Using classroom assessment to maximise student learning. Thousand Oaks, CA: Corwin Press.

Earl, L. \& Katz, S. (2006). Rethinking classroom assessment with purpose in mind. Assessment for learning, assessment as learning, assessment of learning. Western and Northern Canadian Protocol for Collaboration in Education (WNCP). [viewed 1 February 2011] http: / / www.wncp.ca / media / 40539/ rethink.pdf

Griffin, P. (2000). Students! Take your marks, get set, learn. Identifying readiness to learn as a benefit of outcomes based education. Keynote Lecture. Education Queensland Mount Gravatt Symposium Assessment and Reporting in an Outcomes Framework, Mount Gravatt. Assessment Research Centre, University of Melbourne.

Habermas, J. (1996). What is universal pragmatics? In The Habermas Reader. Cambridge: Cambridge University Press, 118-129.

Hatton, N. \& Smith, D. (1995). Reflection in teacher education: Towards definition and implementation. Teaching and Teacher Education, 11(1), 33-49. http: / / dx.doi.org/ 10.1016/0742-051X(94)00012-U 
Huba, M. E. \& Freed, J. E. (2000). Learner-centred assessment on college campus: Shifting the focus from teaching to learning. MA, USA: Allyn and Bacon.

Jenkins, A. (2009). Supporting student development in and beyond the disciplines: The role of the curriculum. (pp. 157-168), In C. Kreber, (Ed.), The university and its disciplines: Teaching and learning within and beyond disciplinary boundaries. New York: Routledge.

Kirkwood, A. \& Price, L. (2008). Assessment and student learning: A fundamental relationship and the role of information and communication technologies. Open Learning: The Journal of Open and Distance Learning, 23(1), 5-16. http: / / dx.doi.org/ 10.1080/ 02680510701815160

Kruger, T., Cherednichenko, B., Hooley, N. \& Moore, R. (2001). Longitudinal study of school restructuring 1996-2000. School of Education, Victoria University of Technology and the Australian National Schools Network, Melbourne.

Kruger, T. \& Cherednichenko B. (2006). Social justice and teacher education: Re-defining the curriculum. International Journal of Learning, 12(7), 321-332.

Lai, Y. C. \& Ng, E. M. W. (2011). Using wikis to develop student teachers' learning, teaching and assessment capabilities. The Internet and Higher Education, 14(1), 15-26. http: / / dx.doi.org/10.1016/j.iheduc.2010.06.001

Larusson, J., \& Alterman, R. (2009). Wiki environments for learning (pp. 137-151). In T. Kidd \& L. Chen, (Eds.), Wired for learning: An educator's guide to Web 2.0. USA: Information Age Publishing.

Marcangelo, C. \& Cartney, P. (2010). The opportunities and challenges of self, peer and group assessment. In M. Hammick \& C. Reid (Eds.) Contemporary issues in assessment in health sciences and Practice Education. Higher Education Academy Assessment Occasional Papers (11). Higher Education Academy. http:/ / eprints.mdx.ac.uk/5490/

Sachs, J. (2003). The activist teaching profession. Buckingham, UK: Open University Press.

Stenhouse, L. (1975). An introduction to curriculum research and development. London: Heinemann.

Authors: Anne Davies has many years experience as a university educator and researcher. She is committed to collaborative practitioner research and has worked with colleagues to study student assessment, school-university partnerships, literacy and numeracy in low socio economic communities and the place of technology in supporting inquiry learning. Postal address: School of Education, St Albans Campus, PO Box 14428 Melbourne VIC 8001. Email: anne.davies@vu.edu.au

Kerry Pantzopoulos has experience as a university educational and policy developer and quality auditor. She has been involved in coordinating and delivering university teaching qualifications, collaborating in the development of blended education programs and researching assessment and work integrated learning. Postal address: Curriculum Innovation Unit, Newport, Campus, Victoria University PO Box 14428, Melbourne VIC 8001. Email: kerry.pantzopoulos@vu.edu.au

Kathleen Gray has many years' experience as a university educator, educational technologist, developer and researcher. She led a national project investigating the use of social web technologies for assessing student learning in higher education. Postal address: Health and Biomedical Informatics Research Unit, Level 1, 202 Berkeley Street, University of Melbourne, VIC 3010. Email: kgray@unimelb.edu.au

Please cite as: Davies, A., Pantzopoulos, K. \& Gray, K. (2011). Emphasising assessment 'as' learning by assessing wiki writing assignments collaboratively and publicly online. In J. Waycott \& J. Sheard (Eds), Assessing students' Web 2.0 activities in higher education. Australasian Journal of Educational Technology, 27(Special issue, 5), 798-812. http: / / www.ascilite.org.au/ajet/ajet27/davies.html 